\title{
Occupational health and safety in Great Britain, 1968
}

\author{
R. E. LANE \\ 3 Daylesford Road, Cheadle, Cheshire
}

The opportunity occurs to review four recent reports to Parliament dealing with the working of safety, health and welfare provisions made for various groups of workers in this country. The reports of the Chief Inspectors of Factories and of Mines have been made for very many years but the other two reports Offices, Shops and Railway Premises, and Agriculture - have appeared only recently as a result of legislation in the last few years.

In all the reports considerable space is devoted to accidents, and this immediately raises the problem of what precisely is to be recorded as an 'accident at work'.Perhaps there were times when the 'lost-time accident' - an absence of more than three days could be regarded as a reasonable criterion of an accident worthy of recording, but the value of this index is now in question. Changes in social conditions over the years have rendered it of little value. In his previous report, the Chief Inspector of Factories advanced cogent arguments against the use of the gross total of these lost-time accidents as an index of safety performance. This is well illustrated by the mining industry, where the fatality rate has been reduced by two-thirds in the last 20 years and the incidence of serious accidents by one-third, whereas during the same period the number of 'lost-time accidents' causing an absence of more than three days has risen by $70 \%$. In the mines these short-term accidents are not used to assess the success of safety precautions. This is done by using only fatal and serious accidents (causing absence of more than 28 days).

It may be argued that this criterion is particularly suitable for a very heavy and dangerous industry, such as mining. While there may be some truth in this, all will welcome the move on the part of the Chief Inspector of Factories to try to collect more accurate information about the nature of the injuries which actually result from reported accidents. At present an enquiry is in progress; this is being carried out on a
$5 \%$ random sample of the accidents reported to the Inspectorate. A few weeks after the accident is reported the employer is asked to supply adequate information about the injury. On this information the accidents will be classified into three groups: (1) those producing injuries which are severe and unambiguously the result of the accident (fractures, burns, etc.); (2) those resulting in absences longer than 28 days but where legitimate doubt exists about the attributability to an accident at work; and (3) those which are similar to (2) but result in absences of less than 28 days. It is hoped that as a result of this analysis a scheme will be devised which will make it possible to make valid comparisons, from year to year, of the results of accident prevention.

A quite separate investigation has also been carried out by the Factory Inspectorate during the year. A small random sample of all accidents has been investigated in depth by the Factory Department. The results are interesting: it is concluded that in some $50 \%$ of accidents 'no reasonable practicable precaution, at least of a physical kind, could have been taken to prevent them, and, secondly, that a very considerable number of the remainder result from poor industrial housekeeping of a kind which is susceptible to improvement by efficient management'. This bears out the strong statement, made by the Chief Inspector of Mines, that 'Production is obtained by the use of men and machines in methods devised and supervised by management. Any assessment of real efficiency must therefore take into consideration the outcome of the way in which men are employed. Safety is not a material factor; it is nebulous and difficult to identify and to define. I would suggest, however, that it can be regarded as a measure of, and one of the rewards for, overall efficiency'.

With this introduction it is proposed to look at the reports individually. Continuing on the theme of accidents, the Chief Inspector of Factories refers to 
the help and co-operation he receives from the oldestablished Royal Society for the Prevention of Accidents and the comparatively new and somewhat unorthodox British Safety Council.

Doubtless both bodies make their contribution to accident prevention as do the special committees set up by particular industries, e.g., foundries, potteries, cotton and allied fibres, wool textile and five other industries. This work is done by joint standing committees which advise the Factory Department and doubtless are advised in their turn.

Emphasis is laid on the safety officer; new standards are suggested for his selection and training which will better enable him to be an expert adviser to management while in no way relieving line management of its day-to-day responsibility for the prevention of accidents.

There were 625 fatal accidents, including 238 in the construction industry. Lack of experience and training was a major factor in a substantial number of the fatal accidents in this industry, including 10 which occurred during the erection or dismantling of lifting machines. There is always a risk of major catastrophe in modern industry because of its increasing scale and the use of dangerous materials in vast quantities. In fact, however, the most serious disaster involving 22 deaths occurred when fire broke out in an upholstery factory in Glasgow. Plastic foam was involved but, had the long-established legal requirements for the maintenance of unimpeded exits in case of fire been observed, those lives need not have been lost - the essential fire exit doors were padlocked!

The report gives interesting details of new processes - radiography of pipe lines and the use of lasers. Perhaps one of the most interesting chapters in the report is the account of the training and dayto-day work of the general factory inspector.

The medical section draws attention to the progress made in setting up a very comprehensive prospective survey of cancer in the rubber and cable-making industries. A great variety of rare and special medical hazards are mentioned which are the particular field of the medical inspectors who are now backed by a well-equipped medical laboratory. This laboratory is growing rapidly and is enabling the inspectors to measure risks and to make objective assessments of degrees of poisoning encountered in their work.

A matter of importance to the medical profession is the promise of early legislation which arises out of a recommendation of the Industrial Health Advisory Committee regarding the Appointed Factory Doctor Service. It is promised that when this legislation comes into force much scarce medical manpower, at present spent in examining perfectly healthy young people, will be diverted to more useful and meaningful work. For instance, during 1968 over 400000 of these examinations were carried out and less than 1 in 400 young persons were rejected. Twenty per cent of these rejections were for pediculosis capitis. Under the new scheme adequate time will be available to deal with those young people who are now found to have a medical or surgical disability. Moreover, the establishment of a body of experienced and interested doctors will make possible an employment medical advisory service properly attuned to present and future needs.

Part of the effort of the Factory Inspectorate was devoted to duties under the Shops and Offices and Railway Premises Act. This extends to shops and offices the safety, health and welfare principles so long established in our factories. The report shows that practically all establishments under the Act had been visited by the end of 1968 . Most of this inspection has been carried out by Local Authority Inspectors, many of whom have had the benefit of training and advice from the Factory Department.

It is doubtful if the number of accidents reported $(19000)$ has much significance, as the same old definition of lost-time accident is retained, and it is further admitted that reporting was not satisfactory. It is perhaps surprising to find as many as 39 fatal accidents recorded in this report. The same faults appear to occur in shops and offices as have been familiar over the years in our factories - the dangerous overcrowding of space with materials and merchandise. Doubtless the Factory Inspectorate will use their influence in the future towards establishing the same standards of safety in offices as are applied to factories. It is welcome to see that during the year the same safeguards for lifts as regards construction, maintenance and examination were introduced for the benefit of those working in shops and offices as had long been extended to the factory worker.

The report on Mines and Quarries again is one of a long series. It gives a precise and expert account of the changing dangers in all mines, principally coal, and of the constant vigilance necessary to prevent serious and fatal accidents. For instance, careful analysis conclusively demonstrates a significant rise in the accident rate per hundred thousand man-shifts resulting from underground haulage and transport, a rate which is significantly higher than that produced by falls of ground, traditionally the sphere of greatest risk, and this despite the considerable attention given to this class of accident.

The decision in the mines report to use the serious and fatal accidents as the index of danger of a process has already been referred to. The number of fatal accidents in the year was 115 , which shows a steady fall over the last 10 years in the rate per one hundred thousand man-shifts.

The number of new cases of pneumoconiosis rose slightly (784). This shows a change in the trend over recent years. Modern methods of mechanical mining produce much dust, and a reading of the 
report gives the impression that dust suppression is not always regarded with the same urgency as some of the other hazards; this, of course, is easily understood in view of the nature of the immediate and obvious results of disregarding some of the other safety precautions. Over recent years much effort has been expended on the evaluation of dust-counting methods. It has now been generally accepted that the gravimetric measurement of dust in the respirable size ranges is likely to provide a more accurate assessment of conditions which could give rise to pneumoconiosis.

The same report includes a section on Quarries where output is steadily rising, though the labour force employed falls slowly. During the year accidents (serious and fatal) rose significantly. Again it was the haulage and transport classification that showed up badly. Measures to reduce these accidents are being taken by introducing new quarry vehicle regulations.

The last report for comment is that on the Safety, Health and Welfare and Wages in Agriculture. It stems from the Agriculture (Poisonous Substances) Act 1953 and the Agriculture (Safety, Health and Welfare Provisions) Act 1956. There is still a tendency among townspeople to regard the countryside as peaceful, a place where nothing much happens and certainly far removed from sudden death, severe injury or sophisticated industrial poisons. This pleasant picture has changed rapidly over the last 35 years and is still changing. Mechanization and chemical pesticides have brought new dangers to those who live and work on the land and to their children. In 1968 there were 114 fatal accidents to farm workers as well as 16 to children about farms. The overturning tractor still heads the list of causes. A new Code of Regulations deals with tractor cabs, and some provisions will come into force in September 1970, but it will be September 1977 before all tractors have to conform. The tragic death of children about farms still presents a problem and does not lend itself so readily to control by legislation and inspection as do so many hazards in industry and mining. An imaginative attack on children's safety is reported; competitions for anti-accident poster designs have been carried out in the schools and the prizewinners are listed. Films dealing with electricity dangers on the farm, farmer's lung and gun safety have recently been made available.

The increasing use of dangerous chemicals made the introduction of safe codes of practice essential. New proposals are under consideration. For the most part, these would make mandatory the pesticide safety precautions, which are at present operated by the manufacturers on a voluntary basis. A new Act with wider powers and coverage is envisaged. A similar Act to deal with farm and garden chemicals is also under consideration. It is pleasing to note that this activity does not result from an increase of these accidents for no deaths due to poisoning were reported in agricultural workers during the year. There were 29 incidents of suspected poisoning in which 33 agricultural workers were involved.

It is of interest to note that the Medical Research Council has set up an Ergonomics and Physical Environment Panel (of its Occupational Health Committee) to consider the health and comfort problems of this important industry so long neglected on the health and safety side.

\section{Bibliography}

Annual Report of H.M. Inspector of Factories for 1968 (1969). H.M.S.O., London.

Report of H.M. Chief Inspector of Mines and Quarries for 1968 (1969). H.M.S.O., London.

The Offices, Shops and Railway Premises Act 1963 Report of Secretary of State for Employment and Productivity for 1968 (1969). H.M.S.O., London.

Report on Safety, Health and Welfare and Wages in Agriculture for 1968 (1969). H.M.S.O., London.

Received for publication February 20, 1970. 